\title{
Neuwahlen beim Deutschen Pflegerat
}

\section{Wer wird Präsident/in?}

\begin{abstract}
Der September 2017 steht nicht nur im Zeichen der Bundestagswahlen. Einen für die Pflege wichtigen Termin gibt es bereits ein paar Tage früher: Am 14./15. September 2017 wird das Präsidium des Deutschen Pflegerats (DPR) für die kommenden vier Jahre neu gewählt.
\end{abstract}

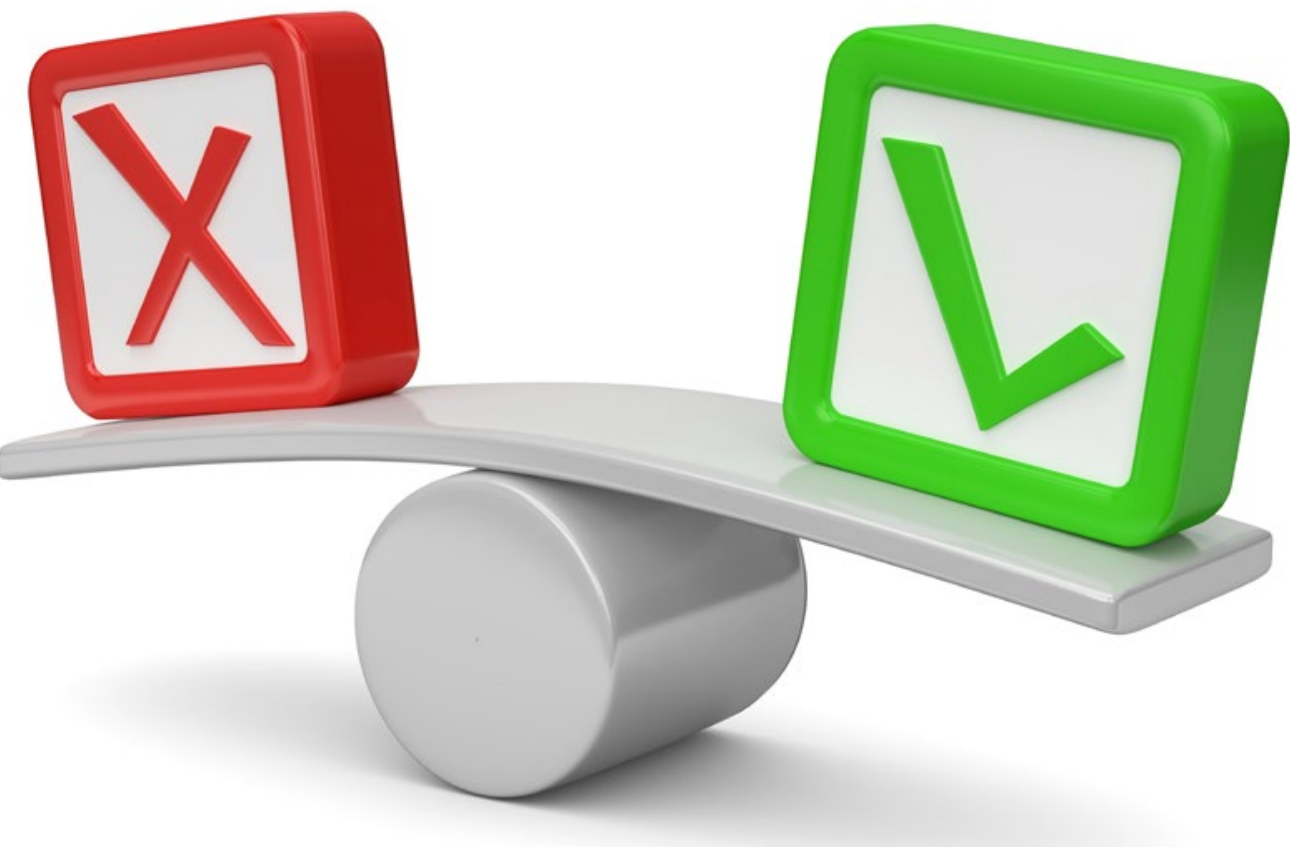

m September wird es einen neuen Präsidenten oder eine neue Präsidentin des DPR geben. Der aktuelle DPRPräsident, Andreas Westerfellhaus, der seit 2009 das Amt in der zweiten Legislaturperiode innehat, darf sich nicht mehr zur Wahl stellen, da nach der Satzung des DPR für den Präsidenten eine Wiederwahl nur einmal möglich ist.

Neu gewählt werden müssen auch die beiden Vize-Präsidenten des DPR sowie das vierköpfige weitere Präsidium. Neben Andreas Westerfellhaus (Präsident) gehören dem derzeitigen Präsidium Franz Wagner (Vize-Präsident) und An- drea Lemke (Vize-Präsidentin) sowie je als Präsidiumsmitglieder Claudia Dachs, Rolf Höfert, Thomas Meißner und Birgit Pätzmann-Sietas an.

\section{Die Aufgaben des Präsidiums}

Die Aufgaben des Präsidiums ergeben sich unmittelbar aus den Aufgaben des Deutschen Pflegerats. $\mathrm{Zu}$ diesen gehört unter anderem die Darstellung der Bedeutung und des Nutzens professioneller Pflege und des Hebammenwesens für ein effektives und effizientes Gesundheitssystem im Interesse der Bevölkerung. Dabei geht es auch um die politische Durchset- zung von pflegeberuflichen Zielen, vor allem auf der Bundesebene als auch innerhalb der Europäischen Union (EU).

Die Mitgestaltung bei Strukturveränderungen, Entwicklungen und Anpassungsprozessen im Gesundheits-, Sozial- und Bildungswesen der Bundesrepublik Deutschland und innerhalb Europas steht gleichfalls im Zentrum der Arbeit des DPR. Dazu gehört auch die Positionierung zu Lohn- und Tariffragen sowie zur entgeltlichen Vergütung professioneller Pflegeleistungen.

Ein weiterer Schwerpunkt der Arbeit des Dachverbandes, und somit auch des Präsidiums, liegt auf der Förderung und Weiterentwicklung der Pflegewissenschaft zum Nutzen des Gesundheitsund Sozialwesens.

Auch die Wahrnehmung von Selbstverwaltungsaufgaben im Gesundheits-, Sozial- und Bildungswesen ist Aufgabe des DPR. Das beinhaltet unter anderem die Initiierung und Förderung einer Qualitätsentwicklung in allen Handlungsfeldern des Gesundheits- und Sozialwesens und die Beschäftigung mit Fragen der Strukturreform und der Qualitätssicherung. Nicht zuletzt nimmt der Deutsche Pflegerat öffentlich Stellung zu aktuellen gesundheits- und pflegepolitischen Fragen und ist dabei direkter Ansprechpartner für die Bundespolitik.

Das Präsidium koordiniert diese und weitere Aufgaben und führt die laufenden Geschäfte des DPR.

\section{Wer wählt das Präsidium?}

Wahlberechtigt für die alle vier Jahre stattfindende Wahl des gesamten Präsidiums sind die Mitglieder der Ratsversammlung. Diese ist das oberste Organ des DPR und besteht aus je zwei Delegierten der aktuell 15 Mitgliedsverbände (und einem Förderverband) des Deutschen Pflegerats und aus dem Präsidium selbst.

www.deutscher-pflegerat.de 